University of Delaware

Disaster Research Center

\author{
PRELIMINARY PAPER \\ \#305 \\ CONTROVERSY AND CONSENSUS IN DISASTER \\ MENTAL HEALTH RESEARCH \\ Kathleen J. Tierney \\ 2000
}


CONTROVERSY AND CONSENSUS IN DISASTER MENTAL HEALTH RESEARCH

Kathleen J. Tierney, Ph. D.

Department of Sociology and Criminal Justice and Disaster Research Center

University of Delaware

Direct Correspondence to:

Kathleen J. Tierney

Disaster Research Center

University of Delaware

Newark, DE 19716

Phone: (302) 831-6618

Fax: (302) 831-2091

e-mail:tierney@udel.edu 


\section{CONTROVERSY AND CONSENSUS IN DISASTER MENTAL HEALTH RESEARCH ${ }^{1}$}

\section{Abstract}

Controversies regarding the mental health consequences of disasters are rooted both in disciplinary orientations and in the widely varied research strategies that have been employed in disaster mental health studies. However, despite a history of dissensus, there are also key issues on which researchers agree. Disasters constitute stressful and traumatic experiences. However, vulnerability to such experiences, as well as to more chronic stressors, is socially structured, reflecting the influence of socioeconomic status and other axes of stratification, including gender, race, and ethnicity. Disaster events differ in the extent to which they generate stress for victims. A holistic perspective on disaster mental health would take into account not only disaster event characteristics, but also social-systemic sources of both acute and chronic stress, secondary and cumulative stressors, and victims' internal and external coping capacities.

Introduction

The question of how disasters affect the mental health of their victims is one that has intrigued researchers almost since the field of disaster research began. Over the approximately four decades during which research has been carried out, different empirical studies and research literatures have offered markedly disparate answers to this question. Depending on which works are consulted, disasters may be characterized as producing negative mental health effects, both positive and negative mental health consequences, or generally positive impacts on psychological well-being (1). However, despite this wide divergence, there are also points on which most researchers who study the psychosocial aspects of disasters seem to agree. This paper begins by

1 This paper is based on a presentation at the UCLA Conference on Public Health and Disasters, Redondo Beach, CA, April 11-14, 1999. 
exploring reasons for the often contradictory findings that appear in the disaster mental health literature. It then goes on to present a perspective on the mental health consequences of disasters that draws upon findings in the fields of disaster research and the sociology of mental health. Divergent Traditions in Disaster Mental Health Research

While the literature on disaster mental health contains many puzzling discrepancies, no one disputes the fact that disaster victims experience real pain and suffering and that disasters can be deeply distressing for those who experience them. Indeed, the disruption of communities, the shattering of lives, and sudden and seemingly senseless deaths and injuries are all part of what makes an event a disaster. Rather, scholarly debates have centered on the extent to which disasters produce identifiable mental health problems in victim populations, and if they do, what it is about disasters that produce those effects, how long those effects typically last, and what factors besides the disaster experience itself are important predictors of post-disaster psychological outcomes. Virtually no definitive conclusions have been made regarding these issues because research findings have been so inconsistent. There are many reasons for this lack of consistency, but for purposes of this discussion, I will somewhat arbitrarily (and some might say simplistically) identify two major sources of the debates and conflicting research conclusions: differences in the disciplinary orientations and theoretical assumptions made by researchers who study disaster-related mental health issues; and differences in the methodologies and research strategies that researchers have employed in their empirical investigations.

It has long been recognized that controversies concerning the prevalence, severity, and duration of disaster-related mental health problems are to at least some degree discipline-based (2-4). Although not always clear-cut, the main disciplinary divisions tend to be between 
psychologically- and clinically-oriented researchers, on the one hand, and sociologically-oriented researchers, on the other. Generally speaking, psychologically-oriented researchers have a greater tendency to characterize disasters as negative in their mental health effects, to see mental health problems as relatively widespread and severe following disasters, and to argue that disasters can have lasting negative mental health effects, even months and years after disaster occurrence. They also tend to conceptualize disasters as events that are capable of producing individual trauma-that is, as similar to other traumatic events like exposure to violence, combat, or extreme lifethreatening experiences--and to look for and find evidence of post-traumatic stress in disaster victims. They generally prefer to focus on symptoms and identifiable disorders, as opposed to more generalized psychological distress or problematic behaviors people may exhibit, such as higher rates of drinking, other substance abuse, or interpersonal violence.

In contrast, sociologically-oriented researchers tend to characterize disasters as having the potential for creating both negative and positive mental health outcomes, to argue that when mental health problems do develop following disasters, they are comparatively rare and mild, and to see problems as transient, generally not extending beyond a few weeks or months after the disaster event. In trying to understand how disasters lead to negative psychosocial outcomes, sociologically-oriented researchers do focus on the traumas to which victims may be exposed during disaster events, but they are equally interested in the contributions made by the broader social context, including social-structural and community-level factors. In addition to being concerned with symptoms and mental disorders, sociologists have a greater tendency than psychologically-oriented researchers to focus on problematic behaviors and manifestations of psychological distress as dependent variables, rather than on specific disorders. 
In addition to these discipline-based differences, research on the mental health consequences of disasters has been characterized by a laundry list of definitional and methodological divergences, making it very difficult to compare or generalize from different studies. For example, studies grouped together under the general disaster label differ widely in what they define as disasters. Events and threats that are grouped under the disaster rubric range from catastrophic and near-catastrophic community-wide natural disasters such as the devastating 1972 Buffalo Creek flood, to disasters involving moderate and less severe impacts, to more localized community emergencies like plane crashes and fires, to technological disasters such as explosions, technological threat situations like Three Mile Island, chronic technological hazards such as the presence of hazardous facilities, episodes of terrorism like the Oklahoma City bombing, and even school-based violence (for examples of these variations, see 5-13, 45).

Studies also differ in terms of how they define disaster victimization. Some studies equate being a disaster victim simply with living in an area where a disaster has occurred. Others take a more detailed look at what actually happened to individuals in disaster situations, attempting to determine, for example, whether the disaster involved losing a loved one, being injured, losing a home or other property, being forced out of a home and into temporary shelter or housing, or experiencing disaster-related unemployment (for an example of this more scientifically sound approach to measuring victimization, see 12) Some empirical work focuses on objective disaster impacts, while other studies assign more importance to individuals' subjective psychological reactions during and after disaster impact.

Research has also varied widely in terms of how dependent variables--that is, mental health outcomes--have been measured. Measurement approaches have ranged from the use of 
rather simplistic and idiosyncratic measures of psychological well-being or impairment to more sophisticated measures using standardized and widely-used measures and indices. Specific indicators also vary widely, from physiological changes indicative of stress, to measures of emotional distress, to indicators of actual mental disorders such as clinical depression, measures of caseness and actual impairment, and indicators of problematic behavioral outcomes such as excessive drinking and interpersonal violence.

Accompanying these differences, there has been considerable variation in the methodological approaches, strategies, and explanatory models used in disaster mental health studies. These include differences in the geographic scope of the areas studied and in the populations selected for study; differences in sampling strategies (e.g., random versus non-random or purposive sampling, groups that are in treatment versus non-treatment populations); variability in the sophistication of the explanatory models used, the number of variables that are taken into account analytically, and the operationalization of those variables; variations in the number of times mental health data were collected, as well as the timing of data collection (for example, cross-sectional versus longitudinal and panel designs, collection of data at different points in time following disasters); and large variations in instruments and data-collection approaches that have been used (clinical interviews, face-to-face epidemiologic interviews, telephone interviews, brief symptom inventories versus lengthier assessment instruments).

Given all these differences, it is perhaps not surprising that findings regarding disaster mental health impacts have varied so widely. Research on the constellation of cognitive and emotional problems that has come to be labeled Post Traumatic Stress Disorder (PTSD) is a case in point. Well-designed epidemiologic studies conducted in non-disaster contexts (see, for 
example, 14) estimate the lifetime prevalence of PTSD at around $5.4 \%$ in the US population, making PTSD one of the more rare mental health disorders. One recent epidemiologic study on the incidence of trauma and the subsequent risk of developing PTSD after experiencing a traumatic event estimates that risk at about 3.8\% for natural disasters (15). However, PTSDrelated findings from studies conducted following different disasters show immense variation, with estimates of the post-disaster incidence of PTSD ranging from very low to over 50\% (see, for example, 16-20). To what extent do these discrepancies reflect real differences, and to what extent are they artifacts of the methods that have been used?

Adding to the confusion, many studies in the literature on mental health and disasters fall considerably short of established standards for good social science research. Among the methodological weaknesses that can be found in the research are the lack of baseline mental health data on the populations under study; the use of small, non-representative, non-random samples; and failure to introduce appropriate controls, both in the form of non- or less-exposed control groups and in the form of appropriate control variables in statistical analyses. There are in fact a surprisingly small number of scientifically rigorous studies on the mental health aspects of disasters; those studies are far outnumbered by others that are methodologically weak. Unfortunately, however, many researchers and practitioners fail to recognize these distinctions, instead treating findings from both well- and poorly-designed studies as more or less equivalent. (For further discussions on differences in study methodologies and findings, see 21, 4).

Despite these limitations, the research that has been conducted on disaster-related mental health issues has expanded our understanding of the origins, nature, and dynamics of the psychosocial problems that accompany disasters. Moreover, theoretical and methodological 
divergences notwithstanding, there is still a considerable amount of agreement on the factors that are important to take into account in understanding the extent to which disasters play a role in generating psychosocial distress. Some of those areas of agreement are discussed in the sections that follow.

\section{A Developing Consensus}

Research in various fields has come to explain the psychosocial consequences of disasters using two different but not mutually exclusive theoretical perspectives: psychosocial stress theory and trauma theory. Disaster is now seen as one among many different types of experiences that can produce stress for those who are involved. Stress is defined in the literature in many ways, but is most commonly understood as "a process in which environmental demands tax or exceed the adaptive capacity of an organism, resulting in psychological and biological changes that may place persons at risk for disease" (22). Relatedly, stressors can be thought of as "conditions of threat, demands, or structural constraints that, by the very fact of their occurrence or existence, call into question the operating integrity of the organism" (23). From the perspective of research on trauma, disaster is seen as one among a range events that can cause traumatic stress, where trauma is conceptualized as "violent encounters with nature, technology, or humankind," in which the traumatic experience is "marked by sudden or extreme force and involves an external agent" (24) Generally speaking, researchers also make a conceptual distinction between stress- or . trauma-producing events and circumstances, which can be measured objectively, and subjective individual responses to those stressful situations.

Much of the earlier work on stress in the fields of health and mental health focused on the importance of stressful events in the genesis of health and mental health problems (25). 
However, the literature also indicates that episodic stressful events, including disasters, must be seen against the backdrop of the ongoing stressful circumstances that people experience throughout their lives. Recent research has increasingly emphasized the idea that psychosocial stressors can range from the acute, such as the loss of a loved one, a major illness, or the experience of a disaster, through the more or less routine, such as the daily hassles that plague people $=\mathrm{s}$ lives, to the chronic, such as the stresses associated with low socioeconomic status and minority group membership. These chronic or systemic sources of stress are thought to account at least in part for the inverse relationship that exists between socioeconomic status and both poor health and psychological distress, a finding that is among the most robust in the research literature (26-28). According to a vast array of studies, it is, quite simply, both physically and psychologically damaging to be on the lower rungs of the status ladder.

In thinking about disasters and their stress-producing potential, it is necessary to keep in mind that both chronic stress and stressful events are also linked to the larger social fabric. Pearlin argues, for example, that (29):

Many stressful experiences...don=t spring out of a vacuum but typically can be traced back to surrounding social structures and people $=\mathrm{s}$ locations within them. The most encompassing of these structures are the various systems of stratification that cut across societies, such as those based on social and economic class, race and ethnicity, gender and age. To the extent that these systems embody the unequal distribution of resources, opportunities, and self-regard, a low status within them may itself be a source of stressful life conditions (242) In other words, exposure to a variety of stressors is part of the reality of marginality and low 
social status. This position is supported by other research showing that vulnerability to undesirable stressful life events is socially structured, in that lower socioeconomic status both exposes individuals to more stress situations and simultaneously appears to rob them of the resources needed to cope successfully with those situations $(30,31)$.

The literature also indicates that other axes of stratification, such as gender and ethnicity, have significant independent effects on individual mental health outcomes. During nondisaster times, for example, women and men differ in the mental health symptoms and problematic behaviors they develop in response to stress (32). Although there is a dearth of good data on many racial and ethnic groups, it is also clear that racial, ethnic, and cultural factors play a role in the genesis of psychological distress and in the ways in which that distress is expressed (33). Relationships are also important; marriage generally acts as a buffer against mental health problems, although more so for men than for women (34). Access to the coping resources that are needed to deal with stress also varies as a function of factors such as ethnicity and social class.

Paralleling studies on the contextual factors that affect mental health outcomes more generally, recent work in the disaster field also reflects an increasing recognition of the role of sociocultural factors in both disaster-related stress and emotional problems that may subsequently develop. For example, Fothergill and Enarson and Morrow have documented the ways in which gender is associated with differential vulnerability both to disaster victimization and to postdisaster stress $(35,36)$. Peacock, Morrow, and Gladwin and Bolin and Stanford have shown how pre-disaster conditions such as income inequality and racial and ethnic discrimination contributed to disaster losses and made recovering from disasters more difficult for affected groups $(37,38)$. In their study on residents of Times Beach, MO who had experienced a flood, dioxin 
contamination, and subsequent relocation, Smith et al.(16) found evidence of slightly elevated symptoms of mental illness. However, they also found that those who were most likely to experience mental health problems tended to be those with lower incomes and fewer years of education, who had also experienced other kinds of stress, and who had exhibited symptoms of emotional distress prior to their exposure to natural and toxic hazards. Similarly, in research on the mental health consequences 1994 Northridge earthquake, D'Souza (39) found that controlling for other variables, including variables related to the severity of earthquake impacts, psychological distress was inversely related to family income. Disaster-induced stressors thus occur against a backdrop of systemic stress that is related in turn to social-structural position.

It is also evident that in addition to being stressful in and of themselves--that is, in addition to acting as primary stressors--disasters also produce other secondary stressors, such as job loss, forced relocation, and economic hardship and uncertainty (40). Disasters may also lead to poor mental health outcomes by reinforcing the socially-structured stress burdens people already experiencing in their everyday lives. These are important issues for further investigation, given empirical evidence indicating that the negative consequences of stress are cumulative. In analyzing the mental health effects of disasters, then, it is important to take into account not only the stressfulness of the disaster experience itself, but also its potential for generating other stressors, as well as how that stress and trauma may be experienced by victims who already differ in the extent to which they are burdened by other acute and chronic sources of stress. (For discussions of the concept of primary and secondary stressors and of the manner in which different sources of stress can reinforce one another, see 29,41$)$.

Using a psychosocial stress perspective calls attention to the importance of better 
understanding how people use coping strategies in their handling of disaster-related problems. Like stress, coping has been defined in various ways, but generally it can be conceptualized involving both intra-psychic processes and external sources of social support that render people more or less resilient in the face of stress (42). Just as coping plays a role in warding off the effects of stress in everyday life, coping and social support clearly play a role in reducing the stress associated with disasters $(43,44)$. It is reasonable to hypothesize that, other things being equal, people who have difficulty coping with stress and problems in living on an everyday basis, whether because of deficits in internal psychological coping abilities, insufficient social support, or the sheer burden of multiple stressors, will be more likely to experience disaster-related emotional distress.

These conceptual frameworks and research findings have clear implications for future research on the relationship between disasters and emotional distress. Studies on disaster-related stress and mental health problems clearly must focus on stress and trauma from the point of view of the individual. For example, it is important to understand how people respond physiologically, emotionally, and cognitively to the stressful circumstances and traumatic events that accompany disasters; to document the phenomenology of those experiences; to focus on psychological factors that render people more or less vulnerable to stress; and to learn more about the intra-psychic processes that help them maintain balance under conditions of excessive threat and demand. At the same time, in conceptualizing and analyzing the impact of stress on psychological well-being, both more generally and with respect to disasters, it is equally important to view individuals not in isolation, but rather in context--that is, taking into account such factors as the individual's social location, the socially-structured availability of coping resources, and broader sociocultural and 
socioeconomic influences on individual mental health outcomes.

The disaster literature also suggests that disaster events themselves vary considerably in their potential for generating psychological distress. Again, thinking of disasters from the perspectives of stress and trauma, different events are not equivalent in terms of the threat, violence, harm, and disruption they generate, or in the extent to which they generate additional stressors for those who are affected. Various researchers have pointed to the importance of taking disaster event characteristics into account in assessing the extent to which people find their disaster experiences emotionally taxing. For example, Bolin (3) outlines several potentially significant ways in which disaster events can differ. First, they differ in the amount of horror and terror victims experience--for example, the feeling of having their lives in danger during impact, or the contact they may be forced to have with dead or mutilated bodies. They also vary in their duration of impact, their suddenness and unexpectedness, and the feelings of immanent and severe threat that they engender. Additionally, disasters vary significantly in their impact ratios, that is, in the extensiveness of the losses and disruption they produce, relative to available community resources. A disaster's impact on the physical environment and the community may be so devastating that social support networks fail to function and the recovery period is lengthy and difficult, causing disaster-related stresses to be amplified. Taking these factors into account, it can be argued that the disaster events that pose the greatest threat to victims' psychological wellbeing are those that generate intense feelings of terror and threat; that occur very suddenly, leaving victims little or no time to prepare or protect themselves, either physically or psychologically; that engender severe loss of life and physical damage; that involve a lengthy period of impact or recurring impacts; that produce a large number of victims, relative to non- 
victims; and that are followed by a lengthy recovery period during which victims are subject to additional hardship and inconvenience. Major disasters like the 1972 Buffalo Creek flood come to mind, as do the 1995 Kobe earthquake and the Casitas volcano collapse in Hurricane Mitch in Nicaragua. The fact that most US disasters fall well outside this catastrophic range may be one reason why negative mental health outcomes tend to be comparatively low in their incidence and severity.

Some researchers believe that natural and technological hazards differ both in their stressfulness and in the extent to which they result in psychological distress for affected populations. They argue that some technological hazards--particularly those associated with toxic and nuclear hazards--are especially pernicious in their psychosocial effects, for several reasons. Typically, the threats associated with these hazards are ambiguous. While they may be extremely damaging and frightening, natural disasters have a beginning and an end. In contrast, the threats associated with toxic hazards tend to persist. People feel anxiety over long periods because they are never sure whether they or their children are safe after having been exposed. Technological hazards are believed to be corrosive for communities, in that they can engender community conflict, undermine social support systems, and disrupt the relationship people have with one another and with the natural environment itself. Blame and recrimination are also typically involved in situations involving toxic hazards, turning community members against one another. Keeping these differences in mind, some researchers claim that crises involving toxic agents may result in more significant mental health problems than natural disasters. Like findings on the mental health consequences of natural disasters, the results of studies on the effects of technological hazards are not consistent with one another. Whether natural and technological 
agents actually do differ in their psychosocial impacts can only be determined through further research. (For other discussions on the natural-technological distinction, see 10, 45-47).

A Holistic Approach to Explaining Post-Disaster Emotional Distress

To summarize the foregoing arguments, despite disciplinary differences, researchers agree that disaster impacts cannot be analyzed in isolation from broader social patterns. Disasters are experienced by individuals who by virtue of their social positions, socially-structured life experiences, and coping capacities, are already differentially vulnerable to psychosocial stress. If the negative effects of chronic and acute stressors are cumulative (and research suggests that they are), then it is reasonable to assume that, other things being equal, individuals and groups have already been exposed to high levels of socially-induced stress will find coping with disasters and the problems they engender even more difficult. Moreover, just as other potentially traumatic events differ in their severity, disasters differ in the impacts they have on vulnerable populations. In hypothesizing about stress and mental health impacts, for example, a flood that damages a few homes and businesses and that results in no deaths and only a small number of injuries simply cannot be equated with a flood that completely destroys entire communities and leaves a path of death and destruction in its wake.

Disasters are commonly conceptualized as involving the convergence of a triggering natural or technological event, a built environment that is unable to withstand the impact of that event, and a vulnerable human population. A meteorological or seismic event that produces only moderate loss and disruption in one societal setting may be catastrophic in another, due to deficiencies in pre-event mitigation and preparedness and/or post-event response and recovery capacity. This same general reasoning can also be applied to the analysis of individual-level 
mental health outcomes following disasters. Other things being equal (and there are numerous other things to consider, which is why research in this area is so difficult), we should expect more severe negative mental health impacts to occur among individuals and groups that are already demonstrably more vulnerable to other types of socially-structured stress. The probability of developing mental health problems following disasters should thus be higher among those who:

- Experience a catastrophic or near-catastrophic disaster event--that is a disaster that produces widespread death and destruction and intense feelings of fear and threat;

- Experience high levels of personal loss, including the loss of loved ones, personal injury, loss of physical possessions, and loss of other sources of social attachment and integration, such as a place of residence or a neighborhood;

- Experience disaster events that so disrupt the physical environment and community systems that household and community recovery are long and protracted, adding to feelings of stress over a prolonged period;

- Experience on an ongoing basis the disadvantages associated with lower social class status or ethnic group membership;

- Lack effective social support networks, or find that those networks are so compromised by disaster that they don't perform their usual stress-buffering functions;

- Lack the psychological resiliency, positive psychological traits, and intra-psychic coping skills that typically afford protection against stressful life events

Outreach and intervention efforts following disasters should take these risk factors into account. Concluding Comments

In conclusion, it is important to put the themes outlined in this paper into context. Quite 
apart from the occurrence of any disaster, psychological distress and varying degrees of psychosocial impairment are very prevalent in the US population. Nearly half of the population has experienced symptoms of at least one Axis I DSM-III-R disorder (a category encompassing mood, anxiety, and addictive disorders) over the course of their lives (14). While painful and debilitating when they occur, most of these symptoms are transient, subsiding on their own without having to be treated. Only a small proportion of the population is plagued by multiple, severe, and chronic psychological disorders. That so many people experience psychological distress at some point in their lives, that the majority continue to function despite those problems, and that people who experience mental health problems adjust, cope, and recover their sense of psychological balance are evidence of the power of internal psychological resiliency and positive external support.

Disasters should be seen as one category of events and circumstances among many that have the potential for heightening stress among affected populations. Experiencing a disaster may well create new sources of stress and contribute to the psychological burdens disaster victims already carry. However, it is likely that like most mental health problems, most disaster-induced symptoms of psychological distress are self-limiting.

These observations are certainly not meant to imply that disaster victims have no need of mental health services, or that we should let those who are having emotional problems in the . aftermath of disasters fend for themselves. They are, however, meant to suggest that in considering strategies for mental health program development and intervention, the highest priority should be given to disaster victims who are already subject to high levels of chronic and acute stress, who had already been manifesting symptoms of psychological disorder prior to 
disaster victimization, who are already having difficulty coping on a daily basis. In a time of shrinking mental health resources, rather than considering all residents of a disaster-stricken area as potentially in need of mental health services, it makes sense to devise programs that target highly vulnerable segments of the population, as well as areas in stricken communities that have experienced extensive disaster damage and disruption.

\section{REFERENCES}

1. Warheit GO: Disasters and Their Mental Health Consequences: Issues, Findings, and Future Trends. In: Lystad M (ed), Mental Health Response to Mass Emergencies: Theory and Practice New York: Brunner/Mazel, 1988, pp 3-21.

2. Tierney K.: Disasters and Mental Health: A Critical Look at Knowledge and Practice. In: Quarantelli EL and Pelanda C (eds), Proceedings of the Italy-United States Seminar on Disasters. Newark, DE: Disaster Research Center University of Delaware, 1989: pp 158-177.

3. Bolin R: Response to natural disasters. In: Lysted (ed), Mental Health Response to Mass Emergencies. New York: Brunner/Mazel, 1988, pp 22-51.

4. Edwards ML: In interdisciplinary perspective on disasters and stress: The promise of an ecological framework. Sociological Forum 1998; 13: 115-132.

5. Erikson KT: Everything In Its Path. New York: Simon and Schuster, 1976.

6. Adams PR, Adams GR: Mount St. Helens's ashfall: Evidence for a disaster stress reaction. American Psychologist 1984; 39: 252-260.

7. Dew MA, Bromet EJ, Schulberg HC: A comparative analysis of two community stressors' long-term mental health effects. American Journal of Community Psychology 1987; 15:167-184. 8. Shore JH, Tatum EL,Vollmer WM: Psychiatric reactions to disaster: The Mt. St. Helen's 
experience. American Journal of Psychiatry 1986; 143: 590-595.

9. Shore JH, ed: Disaster Stress Studies: New Methods and Findings. Washington, DC: American Psychiatric Press, 1986.

10. Freudenburg WR, Jones TR: Attitudes and stress in the presence of technological risk: A test of the Supreme Court hypothesis. Social Forces 1991; 69: 1143-1168.

11. Baum A, Fleming I, Israel A, O'Keefe M: Symptoms of chronic stress following a natural disaster and discovery of a human-made hazard. Environment and Behavior 1992; 24: 347-365.

12. Norris FH, Kaniasty K: Received and perceived social support in times of stress: A test of the social support deterioration deterrence model. Journal of Personality and Social Psychology 1996; 71: 498-511.

13. Gordon NS, Farberow NL, Maida CA: Children and Disasters. Philadelphia: Brunner/Mazel, 1999.

14. Kessler RC, Zhao S: Overview of Descriptive Epidemiology of Mental Disorders. In: Aneshensel CS, Phelan JC (eds), Handbook of the Sociology of Mental Health. New York: Kluwer Academic/Plenum Publishers, 1999, pp 127-150.

15. Breslau N, Kessler RC, Chilcoat HD, Schultz LR, Davis GC, Andreski P: Trauma and posttraumatic stress disorder in the community: The 1996 Detroit Area Survey of trauma. Archives of General Psychiatry 1998; 55: 626-632.

16. Smith E, Robins LN, Przybeck TR, Goldring E, Solomon, SD: Psychosocial Consequences of a Disaster. In: Shore JH (ed), Disaster Stress Studies: New Methods and Findings. Washington, DC: American Psychiatric Press, 1986: pp 50-76.

17. Madakasira S, O’Brien KF: Acute posttraumatic stress disorder in victims of a natural 
disaster. Journal of Nervous and Mental Disease 1987; 175: 286-290.

18. Green BL, Lindy JD: Post-traumatic stress disorder in victims of disasters. Psychiatric Clinics of North America 1994; 17: 301-309.

19. Shannon MP, Lonigan CJ, Finch AJ, Taylor CM: Children exposed to disaster I: Epidemiology of post-traumatic symptoms and symptom profiles. Journal of the American Academy of Child and Adolescent Psychiatry 1994; 33: 80-93.

20. Siegel JM, Shoaf KI, BourqueLB: The C-Mississippi scale for PTSD: A useful measure in post-earthquake communities? International Journal of Mass Emergencies and Disasters forthcoming, 2000: 18 .

21. Rubonis AV, Bickman L: Psychological impairment in the wake of disaster: The disasterpsychopathology relationship. Psychological Bulletin 1991; 109: 384-399.

22. Cohen S, Kessler RC, Gordon, LU: Strategies for Measuring Stress in Studies of Psychiatric and Physical Disorders. In: Cohen S, Kessler RC, Gordon LU (eds), Measuring Stress: A Guide for Health and Social Scientists. New York: Oxford University Press, 1995; pp 3-26.

23. Wheaton B: The Domains and Boundaries of Stress Concepts. In: Kaplan HB, Psychosocial Stress. San Diego: Academic Press, 1996: 29-70.

24. Norris FH: Epidemiology of trauma: Frequency and impact of different potentially traumatic events on different demographic groups. Journal of Consulting and Clinical Psychology 1992; 60: 409-418.

25. Holmes TH, Rahe RH: The social readjustment rating scale. Journal of Psychosomatic Research 1967; 11: 213-218.

26. Mirowsky J, Ross CE: Social patterns of distress. Annual Review of Sociology 1986; 12: 23 - 
45.

27. Williams DR, Takeuchi DT, Adair RK: Socioeconomic status and psychiatric disorder among Blacks and Whites. Social Forces 1992; 71: 179-194.

28. Yu Y, Williams DR: Socioeconomic Status and Mental health. In: Aneshensel CS, Phelan JC (eds), Handbook of the Sociology of Mental Health. New York: Kluwer Academic/Plenum Publishers, 1999, pp 151-166.

29. Pearlin LI: The sociological study of stress. Journal of Health and Social Behavior 1989; 30 : 241-256.

30. McLeod JD, Kessler RC: Socioeconomic status differences in vulnerability to undesirable life events. Journal of Health and Social Behavior 1990; 31: 162-172.

31. Aneshensel CS: Social stress: Theory and research. Annual Review of Sociology 1992; 18 : $15-38$.

32. Aneshensel CS, Rutter, CM, Lachenbruch PA: Social structure, stress, and mental health: Competing conceptual and analytic models. American Sociological Review 1991; 56: 166-178. 33. Vega W, Rumbaut R: Ethnic minorities and mental health. Annual Review of Sociology $1991 ; 17: 351-383$.

34. Ross CE, Mirowsky J, Goldsteen K: The impact of family on health: A decade in review. Journal of Marriage and the Family 1990; 52: 1059-1078.

35. Fothergill A: Gender, risk, and disaster International Journal of Mass Emergencies and Disasters 1996; 14: 33-56.

36. Enarson E, Morrow BW (eds): The Gendered Terrain of Disaster. Westport, CT: Praeger, 1998 
37. Peacock WG, Morrow BH, Gladwin H Hurricane Andrew: Ethnicity, Gender and the Sociology of Disasters. London: Routledge, 1997.

38. Bolin RC with Stanford L: The Northridge Earthquake: Vulnerability and Disaster. London: Routledge, 1998.

39. D'Souza MJJ: Socio-Structural Differentials in the Mental Health Impact of the 1994 Northridge Earthquake. Doctoral Dissertation. Newark, DE: Department of Sociology and Criminal Justice, University of Delaware, 1999.

40. Hutchins GL, Norris, FH: Life change in the disaster recovery period. Environment and Behavior 1989; 21: 33-56.

41. Turner RJ, Lloyd DA: Lifetime traumas and mental health: The significance of cumulative adversity. Journal of Health and Social Behavior 1995; 36:360-376.

42. Lazarus RS, Folkman S: Stress, Appraisal, and Coping. New York: Springer, 1984.

43. Kaniasty K, Norris FH: In search of altruistic community: Patterns of social support mobilization following Hurricane Hugo. American Journal of Community Psychology 1995; 23 : $447-477$.

44. Haines VA, Hurlbert JS, Beggs JJ: The disaster framing of the stress process: A test of an expanded model. International Journal of Mass Emergencies and Disasters 1999; 17: 367-397. 45. Erikson KT: A New Species of Trouble: Explorations in Disaster, Trauma, and Community. New York: W. W. Norton and Company, 1994.

46. Baum A: Toxins, Technology, and Natural Disasters. In Monat A, Lazarus RS (eds.) Stress and Coping: An Anthology, Third Ed. New York: Columbia University Press 1991: pp. 97-139. 47. Tierney K., Lindell, MK, Perry RW: Facing the Unexpected: Disaster Preparedness and 
Response in the United States. Washington, DC: Joseph Henry Press, in press. 
CONTROVERSY AND CONSENSUS IN DISASTER MENTAL HEALTH RESEARCH

KEY WORDS:

DISASTER MENTAL HEALTH;

DISASTERS--PSYCHOSOCIAL IMPACTS;

DISASTER-RELATED STRESS;

DISASTER-RELATED TRAUMA;

DISASTER MENTAL HEALTH RESEARCH;

DISASTER CONSEQUENCES--MENTAL HEALTH 